\title{
EMPRESAS RECUPERADAS EN ARGENTINA DESDE UNA PERSPECTIVA GRAMSCIANA
}

\section{RECOVERED ENTERPRISES IN ARGENTINA FROM A GRAMSCIAN PERSPECTIVE}

\author{
Julieta Mascheroni* \\ Melina Perbellini**
}

\begin{abstract}
RESUMEN
Las empresas recuperadas emergen en Argentina en el contexto abierto por la crisis orgánica desatada en diciembre de 2001. Los trabajadores defendieron sus puestos de trabajo, tomando las fábricas, con el fin de comenzar un proceso de recuperación y puesta en producción. El objetivo de este artículo es analizar el movimiento de las empresas recuperadas a partir de una perspectiva gramsciana, visualizando sus límites y potencialidades para el análisis de este fenómeno.
\end{abstract}

PALABRAS CLAVE: ARGENTINA * RELACIONES LABORALES * CRISIS ECONÓMICA * COOPERATIVA * AUTOGESTIÓN OBRERA

\section{ABSTRACT}

Recovered enterprises in Argentina emerge in the context of the organic crisis that broke out in December 2001. The workers decided to defend their jobs, taking factories, and then begin a recovery process to start producing again. The aim of this study is to analyze the movement of recovered enterprises from a Gramscian perspective, viewing the limits and potential of this theory to the concrete analysis of this phenomenon.

KEYWORDS: ARGENTINA * LABOUR RELATIONS * ECONOMIC CRISIS * COOPERATIVE * WORKERS SELF MANAGEMENT

\footnotetext{
* Centro de Investigaciones y Estudios del Trabajo (сіEт) de la Facultad de Ciencia Política y Relaciones Internacionales de la Universidad Nacional de Rosario (UNR), Argentina. julietamascheroni@gmail.com

** Facultad de Ciencia Política y Relaciones Internacionales de la Universidad Nacional de Rosario (UNR), Argentina. melinaperbellini@gmail.com
} 


\section{INTRODUCCIÓN}

Se ubica la emergencia de las empresas recuperadas en Argentina en el contexto abierto por la crisis orgánica (Gramsci, 1999) que se desató en diciembre de 2001. Este ciclo coincidió con la irrupción de nuevas identidades colectivas que tornaron más complejo y variado el escenario donde se dirimen los intereses en conflicto.

Muchas empresas, tras haber sobrevivido al largo período de la convertibilidad, tambalearon durante la gran crisis declarándose en estado de quiebra. Es en este contexto que los trabajadores decidieron defender sus puestos de trabajo, en primer lugar, tomando las fábricas, para luego, comenzar un duro proceso de recuperación de las mismas y nuevamente su puesta en producción.

Las empresas recuperadas implican una redefinición de las relaciones entre capital-trabajo $y$ la puesta en acto de relaciones sociales fundadas en nuevos valores. Estas muestran que las relaciones sociales de trabajo, sin dejar de estar incorporadas en una sociedad donde el capital-trabajo sigue siendo su principal contradicción, han desandado las estructuraciones tradicionales $y$ ofrecen un proceso de construcción de nuevas formas de asociatividad laboral.

El objetivo de este estudio es analizar el movimiento de las empresas recuperadas a partir de una perspectiva gramsciana, visualizando los límites y potencialidades de esta teoría para el análisis concreto de este fenómeno. Para esto se consideran las reflexiones de Antonio Gramsci en torno a la aparición de los Consejos de Fábrica en Turín en el año 1920, tomando en cuenta la noción de "crisis orgánica" para analizar el contexto de surgimiento de las empresas, así como, los conceptos de democracia obrera y disciplina para analizar las tensiones internas de estos procesos, una vez que la empresa es puesta en marcha.

Para este análisis se utilizaron las entrevistas abiertas en profundidad realizadas a trabajadores de empresas recuperadas, situadas en el área del Gran Rosario (Santa Fe-Argentina) desde el 2006 al 2012.
CONTEXTO DE APARICIÓN DE LAS EMPRESAS RECUPERADAS: CRISIS DEL 2001 COMO CRISIS ORGÁNICA

El surgimiento de las empresas recuperadas en Argentina - luego de las jornadas del 19 y 20 de diciembre de $2001^{1}$ - no es azaroso. La crisis de 2001 puso fin, no solo al modelo de acumulación basado en la valorización financiera (Basualdo, 2006), sino a la esencia misma del modelo de organización social neoliberal.

Es a partir de 2002, cuando en Argentina, el conflicto social se intensifica a partir de la aparición de los movimientos piqueteros, las asambleas barriales, los cortes de calles $y$ las tomas de fábricas, que más adelante desencadenaron en las denominadas empresas recuperadas.

Siguiendo a Gramsci, se plantea que este es un período de crisis orgánica; ya que se conjugan una gran crisis económica con una crisis de hegemonía de la clase dominante $y$ una aguda crisis social, sin precedentes en Argentina, que marcó el principio del cambio de época.

La idea de cambio de época se puede sostener a partir de la centralidad de dos fenómenos entrelazados: la emergencia de rasgos antagonistas en los movimientos sociales y el paralelo agotamiento de la hegemonía neoliberal. El cambio corresponde a una crisis de una forma de dominación, que tensiona y modifica una relación de poder, reestructurándola o superándola (Madonesi, 2008).

El reordenamiento conservador, surgido a partir de la década del 90 con el denominado Consenso de Washington, se asentó por medio de la realización de un profundo proceso de reestructuración capitalista de corte neoliberal. Luego de la dictadura cívicomilitar, el neoliberalismo pudo presentarse como un consenso inevitable, pretendiendo

$1 \quad$ El 19 y 20 de diciembre de 2001, el pueblo argentino salió a las calles a manifestar su descontento hacia el gobierno de Fernando De la Rúa, dando fin a este. El colapso del modelo neoliberal, surgido con la dictadura cívico-militar de 1976 y consolidado en los gobiernos de Carlos Menem (1989-1999) y de Fernando De la Rúa (1999-2001), concluyó con una profunda crisis política, social y económica, que constituyó el preludio de una nueva etapa histórica. 
naturalizarse y diluirse en el sentido común. Fue durante los años del "pensamiento único" que se pretendía confirmar la ausencia de alternativas socio-económicas.

Gramsci expone que la crisis orgánica abarca tanto la pérdida de supremacía intelectual y moral, como la posibilidad de los dominantes de hacer avanzar la economía, afectando a la estructura y a la hegemonía creada. Su solución puede venir desde abajo, pero también desde arriba. Es una crisis del Estado en su conjunto, donde la clase dirigente ve puesta en tela de juicio su autoridad, sea por un fracaso propio en una empresa política de envergadura, sea por la movilización activa $y$ consciente de amplias capas sociales antes inactivas (Campione, 2007).

Siguiendo a Gramsci, se plantea que la forma particular de civilización, de cultura y de moral que la clase dirigente ha representado, se descompone con la desaparición de un modo de vivir $y$ pensar que no puede producirse sin crisis (Campione, 2007). Asimismo, señala que "la crisis consiste precisamente en el hecho de que lo viejo muere $y$ lo nuevo no puede nacer: en este interregno se verifican los fenómenos morbosos más variados" (Gramsci, 1999: 37).

Es en este momento que se abren grandes posibilidades para que aparezcan alternativas ideológicas y políticas más "extrañas". Al mismo tiempo, se generan condiciones para la introducción de transformaciones decisivas impulsadas "desde abajo", siempre que existan fuerzas activas $y$ organizadas que puedan ser portadoras de esos cambios (Campione, 2007).

A partir de esta lectura, se plantea que el desmantelamiento de la hegemonía neoliberal en Argentina, desencadenó en una crisis orgánica que abrió las posibilidades de una disputa de poder. En este escenario de crisis surgen las empresas recuperadas como experiencias asociativas que cuestionan a la autoridad de la figura patronal en el momento en que este comienza a incumplir su rol en la relación capitaltrabajo (al retirarse e intentar vaciar la fábrica). Los trabajadores deciden entonces la toma de las mismas, poniendo en tela de juicio la propia división capital-trabajo y patrón-trabajador.
El próximo apartado se centra en las reflexiones de Antonio Gramsci a raíz de la aparición de los Consejos de Fábrica en Turín en el año 1920, con el fin de considerar los elementos que analicen las empresas recuperadas, teniendo presente la diversidad de los contextos de aparición de estas experiencias de autogestión.

\section{CONSEJOS OBREROS Y EMPRESAS RECUPERADAS: DIFERENTES EXPERIENCIAS DE AUTOGESTIÓN}

Gramsci realizó una importante reflexión sobre el proceso de autogobierno y autogestión obrera a partir del análisis del movimiento obrero acontecido entre 1919 y 1920, la cual dio lugar a la formación de órganos de autogobierno específicamente obreros, los "consejos", que en 1920, alcanzan el control efectivo de las principales fábricas.

En este análisis gramsciano, se encuentran las primeras reflexiones sobre experiencias autogestivas que tomarán más relieve a partir de la experiencia Yugoslava de los 50, generando múltiples debates en torno a este concepto. Si bien, no hay un consenso respecto de la definición del mismo, hay algo con lo que los diferentes autores concuerdan: "las experiencias autogestionarias siempre estuvieron relacionadas a las luchas de los trabajadores $y$, principalmente, del movimiento obrero" (Alburquerque, 2004: 41).

Específicamente, Gramsci se centrará en los procesos surgidos en Turín (Torino), una ciudad industrial (preeminentemente metalúrgica), caracterizada por la producción de automóviles. La principal empresa era Fiat, ocupando a más de 35000 obreros.

En el contexto de la Europa de postguerra de los años 20, como consecuencia de la adaptación de la industria bélica a una economía de paz, las ganancias obtenidas por los empresarios se redujeron considerablemente. Buscando recuperarlas, redujeron salarios y despidieron a miles de obreros, quienes respondieron ocupando los establecimientos y conformando Consejos de Fábrica en cada unidad productiva, con el fin de controlar la producción - recogiendo la experiencia sovietista (Ciolli, 2009). 
Tal y como recopilará Fernández (2001) de los escritos de Gramsci, los Consejos Obreros de esos años compartieron una serie de características, aun dentro de su diversidad. Entre las mismas pueden mencionarse:

1) La práctica de la democracia directa entre los trabajadores a través de la elección de delegados o representantes obreros en asambleas de taller y de fábrica.

2) La revocabilidad constante de los mandatos o delegaciones como forma de freno a la burocratización y el caciquismo.

3) El intento de superación de la división entre obreros organizados y no organizados sindicalmente, así como, entre los diferentes niveles y categorías de la producción.

4) La superación de la organización obrera por oficios como forma de sindicación anticuada.

5) La afirmación de la primacía de la lucha en la fábrica y por consiguiente, la necesidad de que la dirección de la lucha obrera estuviera en la fábrica.

6) El intento de demostrar la posibilidad de la gestión obrera de la producción con prescindencia de los capitalistas propietarios de los medios de producción.

El objetivo último de los Consejos de Fábrica y de su práctica autogestiva, sería abolir la distinción entre poder político y poder económico, logrando la emancipación y autonomía de los trabajadores considerados en su unidad, como productores, los cuales serán simultáneamente administrados y administradores, permitiendo su propio desarrollo orgánico; es decir, la potencialidad de los Consejos deriva de su posibilidad de constituirse como órgano unificador de la clase en el lugar de la producción, superando la escisión productorciudadano sobre la que la burguesía reproduce su dominación. Se trataría de creaciones revolucionarias que parten del lugar de trabajo $y$ se cimentan en el momento de la producción (Laso, 1976). De este modo: "los consejos obreros, los soviets y otras experiencias similares fueron momentos extraordinarios en que los trabajadores ejercieron poder colectivo al interior de la fábrica pero con una fuerte proyección política hacia su exterior" (Ruggeri, 2010).

Estos consejos nacieron en la fábrica, donde las relaciones de explotación son evidentes. Por ello, para Gramsci, su acción política puede trascender los límites de las relaciones contractuales. La democracia obrera llevada allí adelante es el modo de organización de la clase trabajadora (Ciolli, 2009).

Gramsci menciona que los sistemas de democracia obrera dentro de las fábricas se erigirían en escuelas de experiencia política $y$ administrativa, las cuales darían forma $y$ disciplina a las masas, encuadrándolas y brindándoles cohesión (Gramsci, 2004a: 61); es decir, los Consejos Obreros permitirían la práctica de nuevos mecanismos de gestión encaminados a la construcción de un nuevo sistema social y político.

De esta manera, el nacimiento de los Consejos de Fábrica representa para el autor, un hito en un proceso histórico que culminará en la conformación de la Internacional Comunista y la consecuente reorganización de la economía y la convivencia humana a nivel mundial. Esto sucede en el sentido en que los mismos propician la fusión de los distintos equipos, secciones y momentos de la producción, así como de las distintas unidades productivas. De este modo, para Gramsci, el fin último de estas acciones era necesariamente, la conformación del estado obrero:

...toda la clase obrera, tal como se encuentra en la fábrica, comienza una acción que tiene que desembocar necesariamente en la fundación de un estado obrero, que tiene que conducir necesariamente a configurar una sociedad humana de una forma absolutamente original, de forma universal que abarca toda la Internacional obrera, $y$, por tanto, toda la humanidad (Gramsci, 2004b: 79).

Siguiendo a Wyczykier (2009) se plantea que para el análisis de la problemática de la autogestión, es necesario realizar una diferencia entre las experiencias autogestionarias que han buscado la instauración de un modelo 
social, político y económico que favoreciera la transformación y la superación de las relaciones de dominación capitalista, tal como pretendía Gramsci, al analizar los Consejos de Fábrica surgidos en Turín; así como, las experiencias de relaciones obreras democráticas en los países socialistas, como la experiencia yugoslava de la década del 50 y por último, las experiencias que se centran en la reproducción de prácticas autogestivas al interior de la esfera productiva sin connotaciones acerca de un cambio profundo de este modelo de acumulación, como parecería ser el caso de las empresas recuperadas.

A partir de lo mencionado, se sostiene que las empresas recuperadas constituyen experiencias autogestivas que si bien no buscan - tal como pretendía Gramsci con los Consejos Obreros- un cambio social y político, se han tornado innovadoras al cuestionar la relación capital/trabajo. Del mismo modo, se incluye la postura de Ruggeri (2010) quien sostiene que:

Interpretarlas en clave de reconstitución del sistema capitalista por no poder avanzar hacia la revolución socialista es menospreciar no sólo la experiencia y la lucha allí desarrollada... Y aún más importante que eso, es desconocer y despreciar los enormes sacrificios realizados por los trabajadores que consiguen hacer operar empresas abandonadas por los propios capitalistas (2010: 95).

Desde esta postura, se busca observar cómo algunos ejes prefigurados por Gramsci, operan en las empresas recuperadas y más específicamente, en nuestros casos de estudio. Para esto se retomarán los elementos comunes a los Consejos previamente expuestos.

Fernández (2001) marcará como un elemento común en el funcionamiento de los Consejos, la práctica de la democracia directa a partir de la elección de delegados en Asamblea. Al respecto, cabe recalcar que si bien, en los casos relevados se respeta la instancia asamblearia para la toma de decisiones (propia del funcionamiento cooperativo) no todos los trabajadores se involucran del mismo modo, otros no participan de estas y en algunos casos, las instancias decisorias no se encuentran abiertas a la participación de todos los trabajadores de la empresa ${ }^{2}$.

A partir de distintas entrevistas, se observó que aunque algunos trabajadores votan en las elecciones de autoridades de la Cooperativa $y$ toman parte de algunas decisiones asamblearias, no poseen un verdadero conocimiento acerca del funcionamiento de la Cooperativa. Del mismo modo, no participan de la toma de las decisiones más neurálgicas de la empresa ni de su área productiva. Algunas de estas cuestiones pueden observarse en los siguientes extractos de las charlas mantenidas con los trabajadores:

- A veces se hacen asambleas que estamos todos. Pero si no, las decisiones las toman la directiva, el Consejo que hay. Las decisiones de los trabajos, o esas cosas no las tomamos nosotros (Trabajadora C. de empresa cristalera, 2010).

- El Consejo es el que decide junto con los directivos, son ellos los que realmente toman las decisiones (Trabajadora B. de empresa cristalera, 2009).

Como contraparte, se puede decir que al no haber participación de determinados sectores de la empresa en las decisiones, la dirigencia que toma estas decisiones tiende a autonomizarse y en algunos casos, vuelve a asumir la figura patronal. De este modo, se observa una continuidad entre las problemáticas planteadas por Gramsci en los años 20 y las que afectan hoy a estas experiencias autogestivas en relación con la permanencia en los puestos de dirección de ciertos trabajadores que realiza la delegación, generando una burocratización interna y caciquismo, lo cual podría ser evitado con la rotación de los mandatos.

Si bien, se observa a partir de estos señalamientos, que el funcionamiento asambleario

$2 \quad$ Se hace referencia puntual a una empresa en la que no todos los trabajadores se encuentran asociados a la cooperativa. En este caso, solo los socios participan de las Asambleas y la toma de decisiones, excluyendo a aquellos que se hallan en condición de contratados. 
dista de ser el ideal, interesa resaltar junto con Fernández y Borakievich (2007) que los dispositivos asamblearios de democracia directa que han asumido los trabajadores de empresas recuperadas, han sido una de las más fuertes condiciones de posibilidad para producir, inventar $y$ recuperar nuevas disposiciones para la acción. Estos procesos, denominados de recuperación de la imaginación y la acción colectiva, "se vuelven posibles cuando las horizontalidades puestas en juego permiten el registro de las potencias deseantes de cada quien con otros, es decir, despliegan una corriente de fuerzas, de nuevas sinergias hasta entonces adormecidas en las lógicas fabriles tradicionales" (2007: 11).

Prosiguiendo con este análisis, resulta importante destacar que a diferencia de los Consejos, las empresas recuperadas no surgen como parte de un proceso de reivindicación sindical, sino como consecuencia del quiebre de la relación salarial. De la misma forma, no se observa en estos procesos una proyección política y económica, sino una reacción ante la pérdida de las fuentes de trabajo y sustento. De este modo, se infieren las diferencias que generará en la voluntad y el deseo de estos trabajadores de ponerse a cargo del funcionamiento de la empresa. Otro tanto puede decirse acerca de la elección de la forma cooperativa de trabajo.

En el caso de las empresas recuperadas y específicamente, en los casos de estudio, la elección de forma cooperativa de gestión se da por las exigencias legales al momento de poner en marcha la producción para el sostenimiento de la fuente laboral. De acuerdo al marco legal, la Cooperativa de Trabajo se constituye en el modo jurídico de legalizar su situación de ocupantes de la empresa fallida. No se puede de este modo hablar de la existencia de un proyecto sociopolítico ni de la re-elaboración de elementos simbólicos, cognitivos e ideológicos. Esto puede observase en los siguientes fragmentos de charlas con trabajadores de estas empresas:

Todos sabemos cómo surgen este tipo de empresas, que es en función de una necesidad, no en función del conocimiento y compartir ideas en común, sino que surge por la pérdida de trabajo de forma sistemática, por las distintas políticas de los gobiernos neoliberales (Trabajador D. empresa cristalera, 2010).

- Nosotros no es que un día decidimos, bueno, vamos a trabajar todos juntos $y$ ser socios porque realmente veíamos que esto iba a funcionar y que íbamos a formar una cooperativa. Nosotros formamos una cooperativa porque si no nos quedábamos todos en la calle y la única forma legal de seguir funcionando era como cooperativa, así que no fue una elección (Trabajadora A. de empresa láctea, 2010).

Esto se formó una cooperativa por un hecho de necesidad $y$ no todos saben lo que es una cooperativa... nosotros no tenemos ese gran conocimiento de cooperativas, hicimos la cooperativa $y$ lo único que hacemos es trabajar (Trabajador A. de empresa de pastas, 2010).

Retomando otro de los elementos antes mencionados acerca del funcionamiento de los Consejos, específicamente, el referido a la superación de la división entre diferentes niveles y categorías de la producción, interesa remarcar que la misma se constituye en otra compleja faceta de la constitución de la empresa como colectivo; específicamente, a raíz de la persistencia de la separación tradicional de la empresa capitalista entre trabajo manualproducción (trabajadores) y gestión-administración (patronal). Como se señaló en trabajos anteriores (Dicapua, Mascheroni y Perbellini, 2013), para los trabajadores de producción, las tareas de gestión no son trabajo: tal como pensaban de su patrón, como no-trabajador. No se trata solo de una cuestión funcional, sino que en la misma contempla la construcción de su identidad como trabajador-productor, la cual se define por la oposición al patrón-no productor. Como señaló uno de los entrevistados: "-nosotros estamos para trabajar y vivir, $y$ hacer lo máximo posible, lo demás lo tiene que hacer la empresa, la gente que está allá arriba..." (Trabajador A. de empresa cristalera, 2007). 
En el siguiente apartado, se presenta el análisis de estas tensiones y conflictividades internas, a partir del concepto de disciplina propuesto por Gramsci.

\section{LA DEMOCRACIA OBRERA Y LA DISCIPLINA EN LAS EMPRESAS RECUPERADAS}

Otra noción interesante que se debe rescatar para analizar las empresas recuperadas, es la relación que establece Gramsci entre disciplina y libertad. Para el autor, "adherirse a un movimiento quiere decir asumir una parte de la responsabilidad de los acontecimientos que se preparan, convertirse en artífices directos de esos acontecimientos mismos... Disciplinarse es hacerse independiente y libre" (Gramsci, 2004: 23).

En este caso, la disciplina va a implicar un aprendizaje, un esfuerzo colectivo por parte de la clase trabajadora, una forma de potenciar las energías del pueblo trabajador. Esta disciplina es consciente $y$ voluntaria porque cada uno participa con responsabilidad (Ciolli, 2009).

Para Gramsci, la masa obrera tiene que prepararse para conseguir el pleno dominio de sí misma y el primer paso en este camino consiste en disciplinarse en la fábrica, de modo autónomo, espontáneo y libre. Es así que "la disciplina que pediréis a la masa obrera será distinta de la que el patrono imponía y pretendía basado en el derecho de propiedad que constituye en sí mismo una posición de privilegio. Vosotros os basaréis en otro derecho: el del trabajo" (Gramsci, 2004: 64-65).

$\mathrm{Al}$ retomar estos conceptos para un análisis de las experiencias actuales, se puede observar que las disciplinas como responsabilidad y compromiso aparecen fuertemente en los discursos de los trabajadores de empresas recuperadas:

Al principio yo tengo la sensación de que se produjo como una situación de anarquismo, cada uno creía que podía hacer las cosas, como que al no estar la figura patronal, como que no había nada, no hay leyes, no hay nadie que me diga que tengo que hacer... hasta que se dieron cuenta que no, que las cosas no eran así, que también ellos tenían su responsabilidad (Trabajadora A. de empresa láctea, 2010).

- Necesitamos pautas de trabajo, necesitamos una organización, un ordenamiento, porque si no es imposible, es la única forma (Trabajadora B. de fábrica de pastas, 2010).

Es necesario marcar que esta disciplina en conjunto con la libertad, se distancia del disciplinamiento que impone el patrón basado en el derecho de propiedad. Esto se observa claramente en los discursos de los trabajadores de las empresas recuperadas:

- Ahora tenés más responsabilidad. Antes tu patrón te decía: depositá este cheque en tal banco $y$ vos ibas $y$ lo depositabas simplemente porque él te lo decía. Ahora tenés que decidir vos, porque vos sos la responsable de esto (Trabajadora E. de empresa cristalera, 2010).

- Si antes me decían a mí, mirá que esto es azul y yo sabía que no era azul, pero como era el dueño, yo le decía bueno está bien. Ahora yo sé que es así y peleo porque sea así. Si el disco es redondo, sácalo redondo, no lo saqués cuadrado. Por eso peleo. Ahora siento más responsabilidad (Trabajador A. de fábrica de pasta, 2010).

En los Consejos de Fábrica, Gramsci observaba que una de las rupturas más importantes era que el Consejo se iba a nuclear de productores $-y$ no de asalariados - orientados a dirigir el proceso de producción; sin embargo, este paso en las empresas recuperadas no es nada fácil. Se observa que los trabajadores han sido socializados en una relación salarial, conformando sus habitus desde ahí. Su socialización salarial de origen - marcada por una lógica fabril capitalista disciplinaria - aparece como un obstáculo para la construcción de su identidad como trabajadores autogestionados.

Tal como lo plantea Gramsci (2004), el obrero tenía la convicción de la necesidad del propietario, cuya persona se identificaba con la 
persona del industrial, con la persona del gestor responsable de la producción y por lo tanto, también de su salario, de su pan, de su ropa, de su techo, entre otros.

Esto se ejemplifica claramente cuando un trabajador decía: "-YYo no elegí dejar de ser asalariado, a mí no me entró en la cabeza que no soy más asalariado" (Trabajador B. de empresa láctea, 2012).

Tal como se planteó en un artículo anterior (Dicapua et ál., 2013) los trabajadores de empresas recuperadas no contaban con elementos simbólicos, cognitivos e ideológicos que les permitieran comprender la magnitud de la transformación emprendida: pasar de un conjunto de trabajadores asalariados, coordinados por la coacción y el disciplinamiento patronal a trabajadores autogestionados, autónomos para la organización y gestión productiva (Dicapua et ál., 2013).

Esto va a marcar dentro de la fábrica, los diferentes grados de compromisos que asumen los trabajadores. Las empresas recuperadas devienen espacios complejos donde coexisten algunos rasgos de la empresa tradicional y yuxtapuestos a aquellos, los propios de una comunidad de trabajo autogestionaria.

Es lo que Fernández y Borakievich (2007) caracterizan como la emergencia de dos polos: la autogestión y en su opuesto, la delegación. El compromiso va a oscilar entre dos extremos: el involucramiento en el proceso autogestionario (participación) o una actitud de acompañamiento (delegación). La actitud de acompañamiento pasa por reducir la participación a lo estrictamente acordado (las tareas según el puesto de trabajo), como se aprecia en los siguientes extractos de entrevistas:

- Querés que te diga la verdad, a mí me tienen al día. Yo cobro todos los sábados. No gano mucho, pero me pagan. No gano una locura pero cobro (Trabajador A. de empresa cristalera, 2007).

- Yo sigo siendo empleado. Es decir, yo tengo que cumplir mi función. Por ejemplo, a mí me toca la parte de limpieza del comedor (Trabajador A. de supermercado, 2006).
Esto pone en evidencia la socialización previa de estos trabajadores en un modelo salarial, creando habitus de clase que se exteriorizan en prácticas opuestas a estas nuevas formas de asociatividad en el trabajo y generando desde la operatividad del sentido práctico, situaciones de conflicto y tensión, relacionado estrechamente con los diferentes grados de compromiso en el proceso.

\section{- La idea que todos somos iguales, que estamos en el mismo equipo, no todo el mundo tiene puesta esta camiseta. Las peleas son cotidianas, no todos asu- men el compromiso de la misma manera (Trabajador B. de empresa láctea, 2012). \\ - No todos asumen la responsabilidad de la cooperativa, también. ¿Entendés? Todo está en ponerle ganas. Nosotros tenemos que madurar un poquito. Pero como te digo, no todos piensan igual, no todos asumimos la misma responsabili- dad. No todos asumimos que esto es una cooperativa (Trabajadora A. de empresa láctea, 2010)}

Si se retoma la relación que establece Gramsci entre orden y disciplina, se observa junto a Ciolli (2009), que la consolidación de la democracia obrera responde a la necesidad de participación colectiva en las decisiones y al mismo tiempo, a la necesidad de brindar orden $y$ disciplina, que no va a significar la imposición por parte de un grupo, sino por el contrario, es el aprendizaje y el esfuerzo colectivo por dar forma y potenciar las energías del pueblo trabajador: "la democracia obrera permite que la disciplina sea consciente $y$ voluntaria porque cada uno participó con responsabilidad, junto con los otros en su comprensión y formulación" (Ciolli, 2009).

En palabras de Gramsci, de a poco el trabajador va comprendiendo que la fábrica, nacida como ámbito de explotación y disciplinamiento, es el punto de partida de la liberación al quedar en manos de los legítimos productores de la riqueza, a través de su constitución en unidad homogénea y coherente (Campione, 2007). Como lo señala Gramsci: "suscitar en 
la misma fábrica adecuadas secciones de instrucción, verdaderas escuelas profesionales en las que cada obrero, irguiéndose del cansancio que embrutece, pueda abrir la mente al conocimiento de los procesos de producción y mejorarse a sí mismo" (2004: 65).

\section{CONCLUSIONES}

El contexto de surgimiento de las empresas recuperadas en Argentina, parte de la crisis orgánica acontecida en el 2001, lo cual implicó la ruptura de la hegemonía neoliberal y dio origen a diversas formas de contestación al orden político y económico reinante.

Con esta crisis orgánica, la clase dirigente ve puesta en tela de juicio su autoridad, por un fracaso propio o por la movilización activa y consciente de amplias capas sociales. Este mismo cuestionamiento se puede ver reflejado en el momento en que los trabajadores deciden la toma de las fábricas, a raíz del incumplimiento del rol patronal en la división capital-trabajo.

A partir de las reflexiones propuestas por Gramsci en torno a los Consejos de Fábrica, se toman algunos elementos que sirven para pensar sobre el funcionamiento de las empresas recuperadas $y$ las conflictividades para el funcionamiento de estas experiencias autogestivas.

De este modo, se puede observar que el lugar primordial de la democracia directa, la Asamblea, muchas veces no es apropiado por todos los trabajadores, constituyéndose en un ámbito más bien formal, antes que en un espacio de toma de decisiones. De este modo, se pudo observar la persistencia de prácticas delegativas en algunos trabajadores, opuestas a las prácticas autogestivas que han intentado asumir otros. Esto repercute a su vez en la cristalización en los puestos de dirección de las mismas personas, generando una tendencia a la reproducción de la división propia de la empresa tradicional: gestión (administración) - producción (trabajo).

Esto se encuentra íntimamente ligado a la persistencia del habitus asalariado que continúa actuando en las prácticas de los trabajadores. Es aquí donde puede apreciarse el tercer concepto abordado, el de disciplina, el cual permitió observar como varía el compromiso y la responsabilidad de los distintos trabajadores con la tarea común.

Por último, se menciona que si bien, no se cree pertinente asignarles a estas experiencias autogestivas, funciones ni intenciones de cambio global, es importante revalorizar las instancias de aprendizaje que generan.

Desde el ámbito del análisis científicoacadémico, se está de acuerdo con Ruggeri (2010) en que:

La oportunidad que representan las empresas recuperadas por sus trabajadores es hacernos visibles las potencialidades, $y$ también los límites en las presentes circunstancias, de la autogestión como práctica económica y social y como proyecto de cambio del conjunto de la sociedad (2010: 94)

Desde el ámbito de las experiencias concretas de los trabajadores, el aprendizaje se verifica en la posibilidad de ocupar nuevos cargos, con nuevas funciones y nuevas instancias decisorias, todos ellos ligados a la forma cooperativa de trabajo, permitiendo asumir el rol central del trabajador en la producción y gestión de las fábricas, modificando la relación capital-trabajo, propia del sistema capitalista. En palabras de una trabajadora: "-Lamentablemente no estábamos preparados para estar como consejo, para estar ocupando los cargos que tenemos ahora, lo aprendimos día a día, pero con esfuerzo, con la ayuda de todos estamos demostrando que se puede" (Trabajadora A. de empresa láctea, 2010).

\section{BIBLIOGRAFÍA}

LIBROS

Alburquerque, Paulo. "Autogestión". La otra economía. A. Cattani (comp.). Buenos Aires, Argentina: Editorial Altamira, 2004.

Basualdo, Eduardo. Estudios de historia económica argentina. Deuda externa y sectores dominantes desde mediados del siglo $x x$ a la actualidad. Buenos Aires, Argentina: flacso-Siglo xxi Editores, 2006. 
Campione, Daniel. Para leer a Gramsci. Buenos Aires, Argentina: Centro Cultural de la Cooperación Floreal Gorini, 2007.

Ciolli, Vanesa. "La autogestión ayer y hoy. Una mirada desde el pensamiento de Antonio Gramsci". La economía de los trabajadores:autogestión y distribución de la riqueza. A. Ruggeri (coord.). Buenos Aires, Argentina. Ediciones de la Cooperativa Chilavert, 2009: 173-193.

Dicapua, María de los Ángeles; Mascheroni, Julieta y Perbellini, Melina. Detrás de la mirilla: trabajo y género en las nuevas formas de asociatividad. Rosario, Argentina: Ediciones del Revés, 2013.

Gramsci, Antonio. Cuadernos de la cárcel. Tomo 2. México: Ediciones Era, 1999.

Gramsci, Antonio. "Democracia obrera". Antología. Buenos Aires, Argentina. Siglo xxi, 2004: 58-62.

Gramsci, Antonio. "El consejo de fábrica". Antología. Buenos Aires, Argentina. Siglo xxi, 2004: 77-82.

Gramsci, Antonio. "Disciplina y libertad". Antología. Buenos Aires, Argentina. Siglo xxI, 2004: 23.

Gramsci, Antonio. "A los comisarios de sección de los talleres Fiat-Centro y Patentes". Antología. Buenos Aires, Argentina. Siglo xxi, 2004: 62-66.

Gramsci, Antonio. "El consejo de fábrica". Antología. Buenos Aires, Argentina. Siglo xxI, 2004: 77-82.

Wyczykier, Gabriela. De la dependencia a la autogestión laboral. Sobre la reconstrucción de experiencias colectivas de trabajo en la Argentina contemporánea. Buenos Aires, Argentina: Prometeo, 2009.

\section{REVISTAS}

Madonesi, Massimo. "Crisis hegemónica y movimientos antagonistas en América Latina. Una lectura gramsciana del cambio de época". A Contracorriente 2 (5). Carolina del Norte, eeuu: nc State University, 2008.

Ruggeri, Andrés. "Autogestión en la Argentina: reflexiones a partir de la experiencia de las empresas recuperadas por sus trabajadores". Visioni LatinoAmericane 3. Italia. Centro Studi per l'America Latina, julio 2010: 81-96.

\section{TEXTOS ELECTRÓNICOS}

Fernández Buey, Francisco. El proyecto ético-político de Gramsci. México: Centro de Investigación e Información Digital, 2001. En: <http://ciid.politicas. unam.mx/estadoampliado/ docuentos/ ProyectoEticoPolitGramsciFdezBuey.pdf> [consultado el 17 de diciembre de 2012].

OTROS

Fernández, A. M. y Borakievich, S. "Fábricas recuperadas. La anomalía autogestiva”. Ponencia presentada en el Primer Encuentro Internacional de Debate: "La economía de los trabajadores: Autogestión y Distribución de la Riqueza". Buenos Aires, Argentina: Facultad de Filosofía y Letras de la Universidad de Buenos Aires (UBA), 2007.

Laso Prieto, J. M. "Vigencia del pensamiento de Gramsci”. El Basilisco 6. España. Eneroabril 1979: 73-83.

\section{ENTREVISTAS}

Trabajador A. Empresa cristalera. Cañada de Gómez, Santa Fe, Argentina. 18 de abril del 2007.

Trabajadora B. Empresa cristalera. Cañada de Gómez, Santa Fe, Argentina. 16 de mayo del 2009.

Trabajadora C. Empresa cristalera. Cañada de Gómez, Santa Fe, Argentina. 27 de noviembre del 2010.

Trabajador D. Empresa cristalera. Cañada de Gómez, Santa Fe, Argentina. 27 de noviembre del 2010.

Trabajadora E. Empresa cristalera. Cañada de Gómez, Santa Fe, Argentina. 27 de noviembre del 2010.

Trabajador A. Empresa de Pastas. Rosario, Santa Fe, Argentina. 23 de noviembre del 2010. 
Trabajadora B. Empresa de Pastas. Rosario, Santa Fe, Argentina. 23 de noviembre del 2010.

Trabajadora A. Empresa láctea. Rosario, Santa $\mathrm{Fe}$, Argentina. 30 de noviembre del 2010.

Trabajador B. Empresa láctea. Rosario, Santa Fe, Argentina. 14 de marzo del 2012.
Trabajador A. Supermercado. Rosario, Santa Fe, Argentina. 8 de agosto de 2006.

Fecha de ingreso:11/10/2013

Fecha de aprobación: 10/12/2013 
